\title{
Triazole derivatives as chamber inhibitors of copper corrosion
}

\author{
O.A. Goncharova, A.Yu. Luchkin, N.N. Andreev, ${ }^{*}$ N.P. Andreeva \\ and S.S. Vesely
}

\author{
A.N. Frumkin Institute of Physical Chemistry and Electrochemistry, Russian Academy \\ of Sciences, Leninsky pr. 31, Moscow, 119071 Russian Federation \\ *E-mail: $\underline{\text { n.andreev@mail.ru }}$
}

\begin{abstract}
A set of physicochemical (ellipsometry, wetting angle measurement), electrochemical (electrochemical impedance spectroscopy, electrochemical polarization measurements) and corrosion methods (recurrent moisture condensation conditions, salt fog) was used to study the properties of adsorption films formed on copper by the chamber method from benzotriazole (BTA), 1,2,4-1H-triazole (TZ), tolyltriazole (TTA), 5-chloro-1,2,3-benzotriazole (Cl-BTA), 3amino- $1 \mathrm{H}-1,2,4$-triazole and 4-amino- $1 \mathrm{H}$-1,2,4-triazole vapors at $100^{\circ} \mathrm{C}$. It was shown that upon one-hour treatment of copper with vapors of these compounds, nanosized hydrophobic adsorption films were formed on it, which hindered the thermal oxide growth but stabilized the passive state of the metal and improved its corrosion resistance. Of various triazole derivatives studied as chamber corrosion inhibitors, BTA and its derivatives can be distinguished. After one-hour chamber treatment of copper, the protective after-effect of their adsorption films grows symbatically with the saturated vapor pressure at the $\mathrm{CT}$ temperature, i.e., in the series BTA $>$ TTA $>\mathrm{Cl}-\mathrm{BTA}$. This may indicate that at $100^{\circ} \mathrm{C}$, there is not enough time for the formation of equilibrium adsorption films on the metal. There are reasons to believe that upon prolonged copper treatment with vapors of substituted benzotriazoles (24 hours or more), equilibrium adsorption films of inhibitors are formed thereon. In this case, the character of the effect of the properties of chamber inhibitors on their protective after-effect changes. Under these conditions, the best metal protection is provided by $\mathrm{Cl}-\mathrm{BTA}$, i.e., the least volatile and most hydrophobic of the substituted benzotriazoles studied.
\end{abstract}

Key words: copper, vapor-phase film, chamber corrosion inhibitors, triazoles, adsorption films, protective after-effect.

Received: October 27, 2018. Published: December 4, 2018

doi: $\underline{10.17675 / 2305-6894-2018-7-4-12}$

\section{Introduction}

Copper finds extensive use in today's industry. However, it is prone to atmospheric corrosion [1] that necessitates special protection measures. Suitable measures include the use of volatile corrosion inhibitors (VCIs) [2-7]. These are compounds with relatively high saturated vapor pressures $\left(p^{0}\right)$. As VCIs evaporate spontaneously, they saturate the space to be protected, reach the metal as a vapor, and form nanosized adsorption films on its surface. These films provide efficient metal protection from atmospheric corrosion 
without changing the geometric dimensions of the articles and do not interfere with their subsequent usage or treatment.

However, the application of VCIs has a few limitations:

- it involves sealing the space to be protected for the entire period of protection. The fact is that adsorption films of a VCI are in dynamic equilibrium with the internal atmosphere of the packing. VCI molecules are continuously desorbed and evaporated from the metal surface. The desorption is replenished by adsorption of the VCI from the atmosphere saturated with inhibitor vapors. In case of leakage, equilibrium is violated, the $\mathrm{VCI}$ is desorbed and evaporates from the surface and from the space being protected, thus protection is violated;

- the formation of adsorption films takes some time that depends on the conditions and VCI nature and may last from a few days to a few weeks. During this period, it is not recommended to expose the metal and VCI source packed together to strong corrosive conditions $[2,4]$;

- inhibitors with $p^{0}<10^{-5} \mathrm{mmHg}$ are practically unusable for traditional vapor-phase metal protection $[2,4]$, and this fact considerably limits the choice of suitable compounds.

A search for a solution to this problem resulted in the creation of so called chamber method for metal protection by inhibitors. In this method, thin adsorption films with longterm protective after-effect (PAE) are formed on the articles by short-term metal treatment with vapors of low-volatile compounds at elevated temperatures. Inhibitors of this kind were called chamber inhibitors (ChIn).

It has been shown [8-14] that films created on metal surfaces upon chamber treatment (CT) can ensure long-term protection from atmospheric corrosion even under drastic conditions. In this case:

- sealing a metal together with an inhibitor inside a chamber is only required for the chamber treatment time $\left(\tau_{\mathrm{CT}}\right)$;

- a short time is required to form adsorption layers,

- the range of inhibitors used for vapor-phase metal protection can be expanded considerably to include low-volatile compounds.

1,2,3-1H-Benzotriazole (BTA) is one of the most popular copper corrosion inhibitors tested both as a VCI and a ChIn. However, other triazole derivatives are also used to inhibit the corrosion of copper and its alloys [15-37].

This article deals with a comparative analysis of the properties of adsorption films formed by the chamber method from vapors of BTA, 1,2,4-1H-triazole (TZ), tolyltriazole (TTA), 5-chloro-1,2,3-benzotriazole (Cl-BTA), 3-amino-1H-1,2,4-triazole (3-AMT) and 4amino-1H-1,2,4-triazole (4-AMT), whose molecular formulas, melting points (m.p.) and $\log P$ values ${ }^{1}$ are presented in Table 1 .

${ }^{1} P$ - distribution coefficients of compounds in octanol-water two-phase system. 
Table 1. Molecular formulas of the ChIn studied, their melting points and $\log P$.

\begin{tabular}{|c|c|c|c|}
\hline ChIn & m.p., ${ }^{\circ} \mathrm{C}$ & $\log P$ & Molecular formula \\
\hline BTA & 98 & 1.34 & \\
\hline TTA & 86 & 1.8 & \\
\hline $\mathrm{TZ}$ & 121 & -0.58 & \\
\hline Cl-BTA & 159 & 2.06 & \\
\hline 3-AMT & 156 & -0.87 & \\
\hline 4-AMT & 84 & -1.38 & \\
\hline
\end{tabular}

\section{Experimental}

The techniques for sample preparation and measurements, the purity of the compounds and the materials used in this study are similar to those reported previously [13].

All the reagents used in this study were of "pure" grade. Samples and electrodes made of $\mathrm{M} 1$ copper $(\mathrm{Cu}>99.9 \%$; $\mathrm{Fe}<0.005 \%$; $\mathrm{Ni}<0.002 \%$; $\mathrm{S}<0.004 \%$; As $<0.002 \%$; $\mathrm{Pb}<$ $0.005 \% ; \mathrm{Zn}<0.004 \% ; \mathrm{Ag}<0.003 \% ; \mathrm{O}<0.05 \% ; \mathrm{Sb}<0.002 \% ; \mathrm{Bi}<0.001 \% ; \mathrm{Sn}<0.002)$ were used in the experiments. Flat specimens had dimensions of 30x50x3 mm. Each specimen had a hole for mounting in the test cells and chambers. Cylindrical electrodes were $10 \mathrm{~mm}$ in diameter. One of their butt-ends had a hole with threading for the mounting rod. Electrodes were embedded in Teflon shells in order to prevent interaction of their side surfaces with the electrolyte during the tests. The lower butt-end of the cylinder served as the working surface.

Prior to a treatment with ChIn vapors, the working surfaces of specimens and/or electrodes were polished with emery papers to a mirror finish, degreased with acetone and dried in air. Further, they were mounted in $0.5 \mathrm{~L}$ sealed glass vessels containing a weighed portion of an inhibitor $(0.5 \mathrm{~g})$. The vessels were placed in a drying chamber heated to $t=$ $100^{\circ} \mathrm{C}$. The exposure time $\tau$ was $1 \mathrm{~h}$, unless specified otherwise. After that, the specimens 
and/or electrodes were withdrawn from the ChIn-containing vessels, kept for $24 \mathrm{~h}$ at room temperature and then tested.

The thickness $(d)$ of films formed on the metal under predefined conditions was measured with a manual Gartner ellipsometer with light beam modulation and advanced light detection. An LSM-S-111-10-NNP25 solid-state laser with diode pumping and a wavelength of $540 \mathrm{~nm}$ was used as the radiation source. During the tests, the variations in ellipsometric angles $\Delta$ and $\Psi$ were recorded:

$$
\delta \Delta=\Delta-\Delta_{0}, \delta \Psi=\Psi-\Psi_{0},
$$

where the $\Delta_{0}$ and $\Psi_{0}$ angles correspond to the initial surface state, while $\Delta$ and $\Psi$ are the values measured after the surface state changed due to chemisorption of ChIn molecules and/or due to oxide growth. The thicknesses of inhibitor and oxide films were calculated using the Ellipsometry Calculation Spread Sheet software (E. Kondoh) in the three-layer model approximation.

The angles of metal surface wetting with distilled water $(\theta)$ were estimated for a droplet $0.002 \mathrm{ml}$ in volume. A droplet was applied on a specimen surface and photographic images were taken with a specialized DCM 300 digital camera. The $\theta$ values were determined in the images using the angle meter available in a graphic editor.

Potentiodynamic experiments were performed using an IPC-pro potentiostat (RF) and a standard three-electrode cell with divided electrode spaces. A platinum wire served as the auxiliary electrode. Potentials $(E)$ were measured against a saturated silver/silver chloride reference electrode and converted to the normal hydrogen scale. The experiments were carried out in borate buffer solution ( $\mathrm{pH}$ 7.36) containing $0.001 \mathrm{M}$ sodium chloride. Electrodes were placed into a cell containing the electrolyte, kept for $5 \mathrm{~min}$ and polarized from the established potential $\left(E_{\mathrm{st}}\right)$ in the anodic and cathodic directions. The potential sweep rate was $0.2 \mathrm{mV} / \mathrm{s}$.

Anodic polarization was performed to a potential that exceeded the breakdown potential $\left(E_{\mathrm{br}}\right)$ by $0.005-0.010 \mathrm{~V}$. Local depassivation of the metal was detected by a sharp increase in the anodic current density $(i)$ or current oscillations. In some cases, the test was interrupted right after oscillations on anodic polarization curves started, in order to confirm by visual inspection that pits have formed. The local depassivation potential $\left(E_{\mathrm{ld}}\right)$ and the "counter-pitting basis" $\left(\Delta E=E_{\mathrm{ld}}-E_{\mathrm{st}}\right)$ were used as the protective effect criteria.

Cathodic polarization was interrupted once the current density $i$ reached 0.002 $0.003 \mathrm{~mA} / \mathrm{cm}^{2}$.

Electrochemical impedance spectra were obtained using a potentiostat of the same brand and a frequency response analyzer (FRA, produced in RF). The experiments were performed in a cell similar to that used in the potentiodynamic experiments. Similarly, a silver chloride reference electrode and a platinum auxiliary electrode were employed, and borate buffer solution with $\mathrm{pH} 7.36$ containing $0.001 \mathrm{M}$ sodium chloride was used as the electrolyte. The electrodes were placed into a cell with the electrolyte and kept for 5 min 
before the measurements that were performed at the open circuit potential. The frequency was varied within $0.1-10^{5} \mathrm{~Hz}$.

Electrochemical impedance parameters were calculated using the following equivalent circuit: $R_{0}\left[C_{1}\left(R_{1}(Z)\right)\right]$ (Figure 1) that is characteristic of corrosion of copper and its alloys covered with an inhibitor [13, 38-43] (Figure 1):

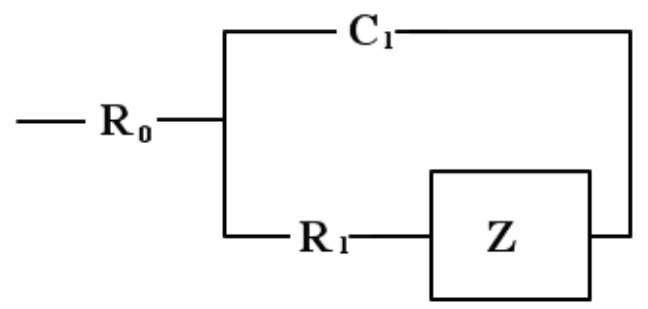

Figure 1. General equivalent circuit used to calculate the impedance parameters.

where $R_{0}$ is the solution resistance, $C_{1}$ is the double layer capacitance, $R_{1}$ is the charge transfer resistance, and $Z$ is the impedance of the surface layers.

The results were processed and impedance parameters were determined using Dummy Circuits Solver software, version 2.1. The fit between the experimental and calculated data was no. worse than $98 \%$.

The degree of a copper electrode protection was calculated using the formula:

$$
z=\left(R_{\text {inh }}-R_{\mathrm{bg}}\right) / R_{\text {inh }} \cdot 100 \%,
$$

where $R_{\mathrm{bg}}$ and $R_{\text {inh }}$ are the total resistances of "copper-electrolyte" interphase interaction, including $R_{1}$ and the surface layer resistance, after thermal treatment (TT) of the electrode in the absence and in the presence of a ChIn, respectively.

The PAE of chamber inhibitors after treatment of samples in their hot vapors was estimated in corrosion tests with recurrent moisture condensation and in a salt fog chamber. The time $\tau$ until the appearance of the first corrosion damage $\left(\tau_{\mathrm{PAE}}\right)$ was recorded in these tests.

In the tests with recurrent moisture condensation on the specimens, the latter were attached with nylon fibers to the lids of airtight glass cells. The cell volume was $600 \mathrm{ml}$. Hot water $\left(50^{\circ} \mathrm{C}, 100 \mathrm{ml}\right)$ was poured into each cell. Once every 24 hours, each cell was opened and the cooled water was replaced with hot water. Water replacement was combined with visual inspection of specimens. During the first 12 hours of exposure, the specimens were inspected every hour without opening the cells.

The tests in neutral salt fog were performed in a WEISS SC 450 chamber at room temperature. Each one-hour test cycle included 15-minute spraying of 3\% $\mathrm{NaCl}$ solution followed by 45 -minute exposure of specimens in the resulting salt fog. Specimens were inspected 55 min after the beginning of each cycle.

All the values presented in this paper are the averages of 5-7 independent experiments. 


\section{Results and Discussion}

The results of ellipsometric measurements presented in Table 2 indicate that the thickness (d) of the air-formed oxide on copper that was not heat treated was $1.0 \mathrm{~nm}$. Heat treatment of specimens for $1 \mathrm{~h}$ at $100^{\circ} \mathrm{C}$ in the absence of a chamber corrosion inhibitor resulted in oxide growth to $4.5-5.0 \mathrm{~nm}$.

Table 2. Effect of copper chamber treatment on the $d$ of surface films.

\begin{tabular}{ccc}
\hline \multirow{2}{*}{ ChIn } & \multicolumn{2}{c}{$\boldsymbol{d , n m}$} \\
\cline { 2 - 3 } & Oxide film & Film of adsorbed ChIn \\
\hline Before treatment & 1.0 & - \\
Without ChIn & $4.5-5.0$ & - \\
TZ & $1.5-2.0$ & $1.0-2.5$ \\
BTA & $1.0-1.5$ & $4.0-5.0$ \\
TTA & $2.0-2.5$ & $1.0-2.0$ \\
Cl-BTA & $1.5-2.0$ & $2.0-3.0$ \\
3-AMT & $2.5-3.0$ & $1.5-2.5$ \\
4-AMT & $1.5-2.0$ & $1.0-2.0$ \\
\hline
\end{tabular}

Upon chamber treatment in the presence of the ChIn studied, adsorption films formed on the oxide surface. The largest $d$ corresponded to BTA $(4.0-5.0 \mathrm{~nm})$ and the smallest, to TTA and 4-AMT $(1.0-2.0 \mathrm{~nm})$. The thickness of the adsorption films formed by the other ChIn varied from 1.0 to $3.0 \mathrm{~nm}$.

These adsorption films markedly inhibited the oxide growth during heat treatment. Its thickness $d$ did not exceed $1.5 \mathrm{~nm}$ on specimens treated with BTA, or $2.0 \mathrm{~nm}$ for TZ, ClBTA or 4-AMT. TTA and 3-AMT hindered oxide growth to the smallest extent: the oxide layer thickness under their films was 2.5 and $3.0 \mathrm{~nm}$, respectively.

The adsorption films of ChIn were multilayered as their thickness was 5-10 larger that the linear size of the ChIn molecules that formed these films.

The formation of such nanosized films resulted in hydrophobization of the copper surface. This is confirmed by the results of $\theta$ measurements (Table 3 ). The copper surface before the CT was hydrophilic and well wettable with water $\left(\theta<40^{\circ}\right)$. Thermal treatment without a ChIn increased $\theta$ to $75^{\circ}$. The maximum hydrophobic effects were provided by BTA and TTA, viz., 104 and $98^{\circ}$, respectively. Treatment of copper electrodes with ClBTA vapors resulted in a $\theta$ increase to $93^{\circ}$. Treatment with hot vapors of TZ, 3-AMT or 4AMT increased $\theta$ by $10^{\circ}$, on average, with respect to the background values. In these cases, the surface remained hydrophilic $\left(\theta<90^{\circ}\right)$. 
Table 3. Effect of copper chamber treatment on $\theta$.

\begin{tabular}{ccccccccc}
\hline ChIn & $\begin{array}{c}\text { before } \\
\text { CT }\end{array}$ & $\begin{array}{c}\text { Without } \\
\text { ChIn }\end{array}$ & TZ & BTA & TTA & Cl-BTA & 3-AMT & 4-AMT \\
\hline$\theta$ & 40 & 75 & 85 & 107 & 98 & 95 & 85 & 85 \\
\hline
\end{tabular}

Potentiodynamic studies (Figure 2, Table 4) have shown that the adsorption films of ChIn formed on copper hinder both electrode processes that determine the metal corrosion.

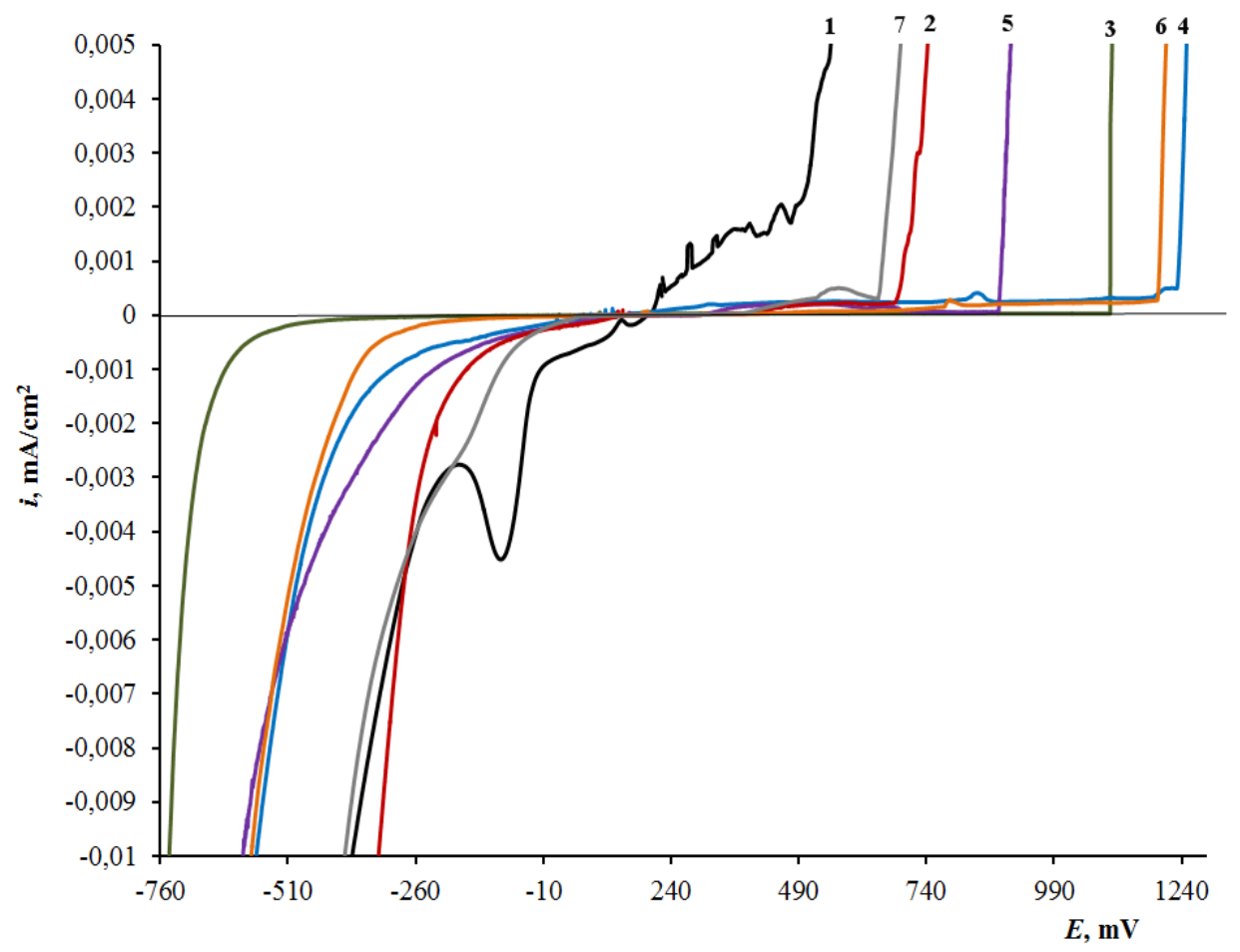

Figure 2. Potentiodynamic polarization curves of copper electrodes after CT without a ChIn 1 , or in the presence of ChIn: TZ - 2, BTA - 3, TTA - 4, Cl-BTA - 5, 3-AMT - 6, 4-AMT 7.

Table 4. Characteristics of polarization curves without CT and in the presence of ChIn.

\begin{tabular}{ccccc}
\hline $\mathbf{C T}$ & $\boldsymbol{E}_{\mathbf{s t}}, \mathbf{m V}$ & $\boldsymbol{E}_{\mathbf{l d}}, \mathbf{m V}$ & $\boldsymbol{E}_{\mathbf{b r}}, \mathbf{m V}$ & $\boldsymbol{\Delta} \boldsymbol{E}, \mathbf{m V}$ \\
\hline Without ChIn & 225 & 270 & 510 & 45 \\
TZ & 117 & 685 & 685 & 568 \\
BTA & 156 & 1100 & 1100 & 944 \\
TTA & 134 & 750 & 1231 & 616 \\
Cl-BTA & 119 & 883 & 883 & 764 \\
3-AMT & 157 & 650 & 1193 & 493 \\
4-AMT & 117 & 515 & 640 & 398 \\
\hline
\end{tabular}


The steady state potential $\left(E_{\mathrm{st}}\right)$ of copper after thermal treatment without a ChIn is $c a$. $0.22 \mathrm{~V}$. All the inhibitors studied shifted it somewhat in negative direction. TZ, Cl-BTA and 4-AMT caused the largest $E_{\text {st }}$ shift (by $0.10 \mathrm{~V}$ ), while BTA and 3-AMT caused the smallest shift (by $0.06 \mathrm{~V}$ ).

The cathodic polarization curves of electrodes that underwent thermal treatment without a ChIn contain a current density $(i)$ maximum, which is apparently due to the reduction of the surface oxide $(E=-0.1 \mathrm{~V})$. This peak disappeared upon addition of a ChIn. It can be assumed that this is due to oxide thinning and formation of adsorbed ChIn layers above it, which prevent oxide reduction. Adsorption films of BTA caused the strongest hindrance of the cathodic process, whereas the films of TZ and 4-AMT caused the weakest hindrance.

The shape of anodic polarization curves was typical of the passive metal. On scanning the potential $E$ of copper that underwent heat treatment without a ChIn in anodic direction, minor $i$ oscillations appeared on the polarization curves at $E_{\mathrm{ld}}=0.27 \mathrm{~V}$ after a short region of passivity. If the electrode was visually inspected after that, local depassivation was noticed: black dots (pits) appeared on the surface. Further anodic polarization was accompanied by an abrupt $i$ increase, i.e., breakdown. The corresponding $E\left(E_{\mathrm{br}}\right)$ was $0.51 \mathrm{~V}$.

Treatment of copper with vapors of the chamber inhibitors studied hindered its local depassivation and increased the length of the passive region. There were no. $i$ oscillations on polarization curves of copper with adsorption films of BTA, Cl-BTA and TZ. Local depassivation of the metal treated with these ChIn manifested itself with an abrupt $i$ growth. In the other cases (TTA, 3-AMT and 4-AMT), pitting confirmed by visual inspection of specimens was accompanied by small oscillations on the anodic polarization curves. The smallest values of $E_{\mathrm{ld}}$ and the counter-pitting basis were observed on electrodes treated with BTA, KhBTA or TTA vapors.

The high protective after-effect of the ChIn studied is also confirmed by the results of electrochemical impedance measurements. Its spectra are presented in Figure 3 in the form of Nyquist plots.

Two regions can be distinguished on the Nyquist plot of a copper electrode heattreated without a ChIn.

In the frequency range of $50-10^{5} \mathrm{~Hz}$ there is a semicircle typical of systems with kinetically controlled charge transfer. In the low frequency region, i.e., $0.1-50 \mathrm{~Hz}$, the plot is a straight line characteristic of a diffusion process related to corrosion in a chloridecontaining medium.

It is expedient to use Warburg impedance $(W)$ for an adequate description of experimental values on this plot $[38,42,43]$. In this case, the equivalent circuit takes the form $R_{0}\left[C_{1}\left(R_{1}\left(C_{2}\left(R_{2} W\right)\right)\right.\right.$ (Figure $4 \mathrm{~A}$ ), where $R_{2}$ and $C_{2}$ correspond to surface layers. 


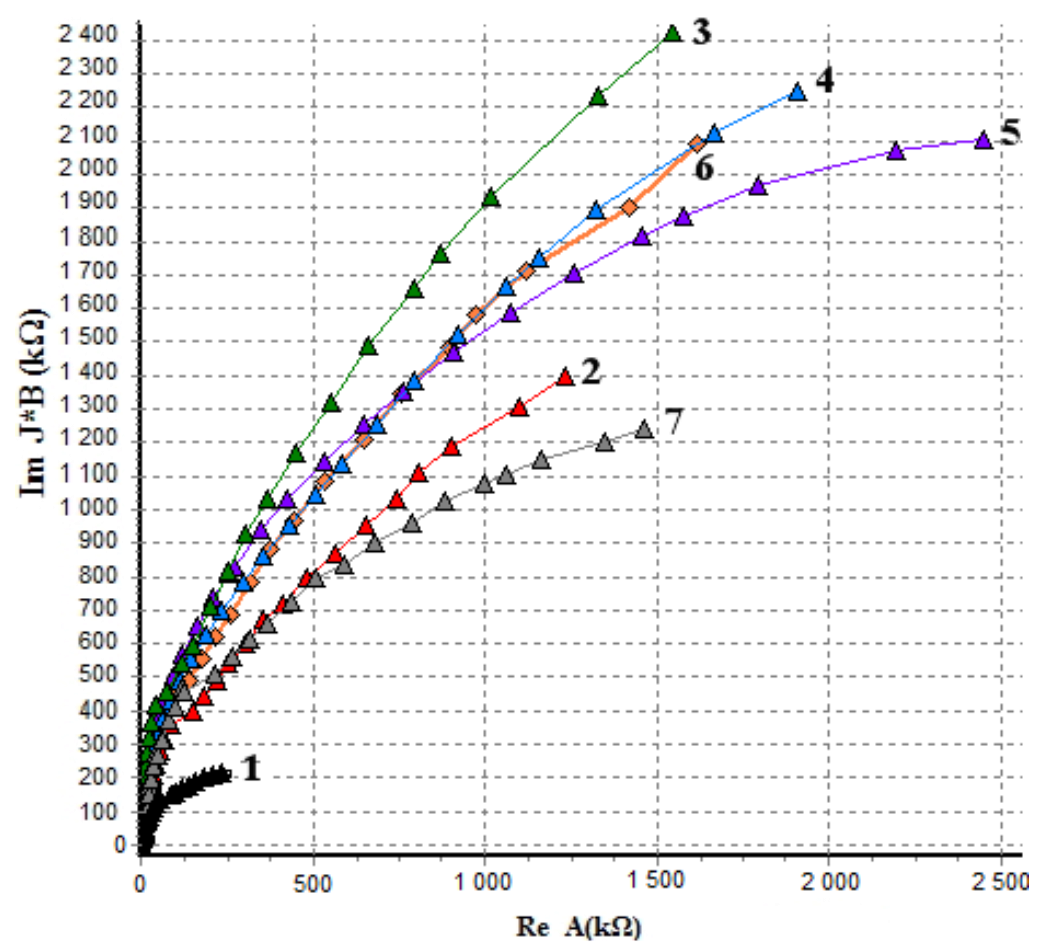

Figure 3. Nyquist plots of copper electrodes after CT without a ChIn - 1, or in the presence of ChIn: TZ - 2, BTA - 3, TTA - 4, Cl-BTA - 5, 3-AMT - 6, 4-AMT - 7.

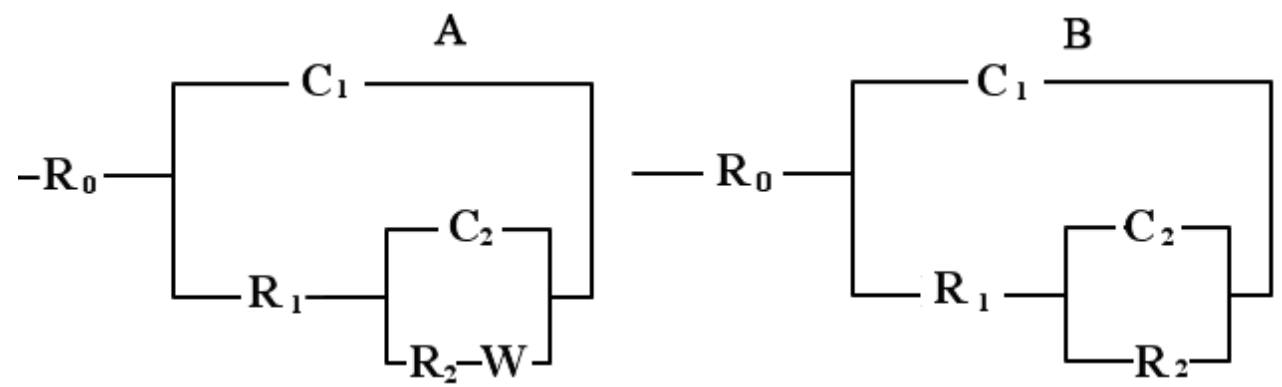

Figure 4. Equivalent circuits used to calculate the impedance parameters: A - CT without ChIn; B - CT with a ChIn.

Chamber treatment of an electrode in hot ChIn vapors changed the Nyquist plot shape and the diffusion component disappeared. In this case, the experimental results were described with high reliability by an $R_{0}\left[C_{1}\left(R_{1}\left(R_{2} C_{2}\right)\right)\right]$ equivalent circuit (Figure $4 \mathrm{~B}$ ). The calculated parameters of this equivalent circuit and the protective efficiency $(z)$ are presented in Table 5.

The $z$ values were calculated with respect to a copper electrode thermally treated without a ChIn.

The $R_{1}$ and $R_{2}$ resistances increased considerably after chamber treatment in the presence of ChIn vapors. The maximum values of these parameters were observed for electrodes treated with BTA. In this case, $R_{1}$ increased 11.4-fold and $R_{2}$ increased 10.9-fold in comparison with the reference values. 
Table 5. Impedance parameters calculated for copper electrodes that underwent various variants of chamber treatment.

\begin{tabular}{cccccccc}
\hline ChIn & $\boldsymbol{R}_{\mathbf{0}}, \mathbf{O h m}$ & $\boldsymbol{R}_{\mathbf{1}}, \mathbf{k O h m}$ & $\boldsymbol{C}_{\mathbf{1}}, \boldsymbol{\mu F}$ & $\boldsymbol{R}_{\mathbf{2}}, \mathbf{k O h m}$ & $\boldsymbol{C}_{\mathbf{2}}, \boldsymbol{\mu} \mathbf{F}$ & $\boldsymbol{W}, \mathbf{k O h m} / \mathbf{s}^{\mathbf{0 . 5}}$ & $\boldsymbol{z}$ \\
\hline None & 471.35 & 200.98 & 0.64 & 213.35 & 2.87 & 112.23 & - \\
TZ & 467.16 & 1272.60 & 0.37 & 1918.81 & 0.71 & - & 83.50 \\
BTA & 462.99 & 2739.91 & 0.35 & 3074.27 & 0.38 & - & 90.94 \\
TTA & 476.47 & 2160.51 & 0.25 & 3247.34 & 0.45 & - & 90.26 \\
Cl-BTA & 461.50 & 2722.98 & 0.22 & 2017.63 & 0.56 & - & 88.89 \\
3-AMT & 478.45 & 2116.34 & 0.33 & 2508.03 & 0.48 & - & 88.61 \\
4-AMT & 462.95 & 1500.73 & 0.29 & 1549.56 & 0.95 & - & 82.74 \\
\hline
\end{tabular}

A somewhat smaller increase in $R_{1}$ and $R_{2}$ is observed in the case of TTA, Cl-BTA and 3-AMT. Treatment with vapors of TTA, 3-AMT and Cl-BTA increased $R_{1}$ 9-, 8.72and 11.3-fold and $R_{2}, 10.5-, 8.85$ and 7.1-fold, respectively. The smallest change in $R_{1}$ and $R_{2}$ values was demonstrated by electrodes treated with TZ or 4-AMT. For these ChIn, the $R_{1}$ values increased 5.3- and 6.2-fold, while the $R_{2}$ values increased 6.8- and 5.5-fold, respectively.

The increase in $R_{1}$ may be interpreted as a decrease in the corrosion rate. The $R_{2}$ growth indicates that charge transfer slows down due to the formation of a protective ChIn layer. At the same time, $z$ values above $90 \%$ were observed for two compounds, namely, BTA and TTA. Cl-BTA and 3-AMT provide lower degrees of protection. The $z$ values in the case of TZ and 4-AMT did not exceed $84 \%$.

Chamber treatment of copper in the presence of ChIn results in a decrease in the double layer capacitance $C_{1}$ since ChIn molecules adsorbing on the metal decrease the fraction of its free surface. The $C_{1}$ decrease is most pronounced for Cl-BTA and TTA. The decrease in $C_{2}$, which is the strongest for BTA and TTA, also indicates that the corrosion rate decreases.

Thus, the results of electrochemical impedance measurements agree with the results of potentiodynamic experiments and demonstrate the high efficiency of copper chamber treatment with BTA and its derivatives. The efficiency of these ChIn (BTA, TTA and ClBTA) was analyzed by accelerated corrosion methods.

Under conditions of recurrent moisture condensation, the specimens that underwent thermal treatment without a ChIn started to corrode in $4 \mathrm{~h}$ after the start of the experiment (Table 6). Inspection of these specimens revealed considerable dark spots and overall staining of the metal surface. Adsorption films of ChIn hindered copper corrosion and prolonged complete metal protection. The maximum protective effect was observed after copper chamber treatment with BTA vapors. In this case, the first indications of corrosion damage appeared on the specimens in 40 days after the experiment start $(\gamma=240)$. TTA is 
less efficient, as its PAE was 28 days $(\gamma=169)$. Cl-BTA provided full metal protection for 21 days $(\gamma=126)$.

Table 6. $\tau_{\mathrm{PAE}}$ under recurrent moisture condensation conditions and in salt fog after $\mathrm{CT}$ of copper specimens for 1 and $24 \mathrm{~h}$.

\begin{tabular}{ccccc}
\hline \multirow{5}{*}{$\boldsymbol{\tau}_{\mathrm{CT}}$} & \multicolumn{4}{c}{$\boldsymbol{\tau}_{\text {PAE }}$} \\
\cline { 2 - 5 } & Background & BTA & TTA & Cl-BTA \\
\hline \multicolumn{5}{c}{ Recurrent moisture condensation } \\
\hline $1 \mathrm{~h}$ & $4 \mathrm{~h}$ & 40 days & 28 days & 21 days \\
\hline \multicolumn{5}{c}{ Salt fog chamber } \\
\hline $1 \mathrm{~h}$ & $2 \mathrm{~h}$ & $30 \mathrm{~h}$ & $28 \mathrm{~h}$ & $22 \mathrm{~h}$ \\
1 day & $3 \mathrm{~h}$ & $44 \mathrm{~h}$ & $40 \mathrm{~h}$ & $49 \mathrm{~h}$ \\
\hline
\end{tabular}

Under salt fog conditions, the first corrosion damage on copper specimens heattreated without a ChIn appeared after 2 one-hour test cycles (Table 6). The corrosion was of local (pitting) type. Chamber treatment with ChIn vapors resulted in a noticeable inhibition of metal depassivation. The maximum protective after-effect was observed for BTA $(30 \mathrm{~h})$ and TTA $(28 \mathrm{~h})$, while the minimum protection was observed in the case of ClBTA $(22 \mathrm{~h})$.

Thus, the efficiency of benzotriazoles as ChIn under conditions of recurrent moisture condensation and in salt fog decreased in the series BTA $>$ TTA $>$ Cl-BTA.

Apparently, the efficiency of chamber treatment of metals with BTA and its derivatives is affected by many characteristics of these compounds. The hydrophobicity and $p^{0}$ of compounds are among these characteristics.

If an equilibrium adsorption film is formed on the metal surface in $\tau_{\mathrm{CT}}$ period of time, it should be expected that the ChIn efficiency would increase upon:

- a decrease in $p^{0}$ at the test temperature, i.e., with an increase in the stability of adsorption films against evaporation from the metal surface;

- an increase in ChIn hydrophobicity, i.e., again, with an increase in the stability of adsorption films in contact with a corrosive electrolyte.

However, the picture can change if equilibrium is not reached during the CT. In this case, an increase in $p^{0}$ at $t_{\mathrm{CT}}$ would facilitate ChIn adsorption and hence increase the PAE.

Under the conditions studied, the efficiency of benzotriazoles as ChIn decreased in parallel with the $p^{0}$ of these compounds at $t_{\text {СТ. }}$. This follows from a comparative estimate of the volatility of these compounds at $100^{\circ} \mathrm{C}$ by the techniques described in [44-49].

The structures of BTA, TTA and Cl-BTA differ only in the substituent at the benzene ring $\left(-\mathrm{H}\right.$ in $\mathrm{BTA},-\mathrm{CH}_{3}$ in TTA and $-\mathrm{Cl}$ in $\left.\mathrm{Cl}-\mathrm{BTA}\right)$. They can be considered as representatives of a single reaction series from the perspective of the linear free energy 
(LFE) principle. These substituents are characterized by the following volatility constants: $\xi_{\mathrm{H}}=0, \xi_{\mathrm{CH}_{3}}=-0.56, \xi_{\mathrm{Cl}}=-0.93$, hence at a constant $t$ (above the melting points of these compounds), the $p^{0}$ of the ChIn in question will decrease in the series: $\mathrm{BTA}>\mathrm{TTA}>\mathrm{Cl}-$ BTA. At $100^{\circ} \mathrm{C}$, only BTA and TTA are in the liquid state of aggregation, whereas ClBTA is a solid compound. However, this fact can only decrease the $p^{0}$ of Cl-BTA with respect to the values estimated from $\xi$-constants and does not affect the order of compounds in the series of decreasing volatility. As a result, it can be stated with certainty that at $100^{\circ} \mathrm{C}$ the $p^{0}$ of the ChIn studied would decrease in the same order as their PAE in the corrosion tests.

The increase in ChIn efficiency with an increase in their $p^{0}$ values indicates that equilibrium adsorption of BTA derivatives on copper is not reached in $1 \mathrm{~h}$ of chamber treatment at $100^{\circ} \mathrm{C}$. It should be reminded that the choice of this duration for the $\mathrm{CT}$ is based on data [13] that the PAE of BTA stabilizes after chamber treatment for 20-40 minutes. However, rather a narrow range of CT durations (up to $1 \mathrm{~h}$ ) was considered in this study. In this case, the change in the PAE of BTA with an increase in CT duration could be insignificant and remained unnoticed.

As experiments show, prolongation of $\mathrm{CT}$ to $24 \mathrm{~h}$ results in an appreciable increase in the PAE of adsorption films in salt fog (Table 6). In fact, the PAE of BTA increases from 30 to $44 \mathrm{~h}$, that of TTA from 28 to $40 \mathrm{~h}$, and that of Cl-BTA from 22 to $49 \mathrm{~h}$. Cl-BTA becomes the most efficient ChIn at this CT duration.

This compound is the least volatile BTA derivative at the test temperatures. Under these conditions, the solid state of aggregation of the ChIn studied makes it difficult to compare $p^{0}$ by LFE methods, however, the lowest volatility constant combined with the highest melting point of this compound support this statement.

Furthermore, Cl-BTA is the most hydrophobic compound in the series we studied, which also favors the stability of adsorption films under the corrosion conditions.

\section{Conclusions}

1. It was shown that upon one-hour treatment of copper with vapors of triazole derivatives at $100^{\circ} \mathrm{C}$, nanosized hydrophobic adsorption films were formed on it, which hindered the thermal oxide growth but stabilized the passive state of the metal and improved its corrosion resistance.

2. Benzotriazole and substituted BTAs are notable as chamber inhibitors among triazole derivatives.

3. The efficiencies of substituted benzotriazoles as ChIn after one-hour copper treatment increases in parallel to the their saturated vapor pressures at the CT temperature in the series: $\mathrm{BTA}>\mathrm{TTA}>\mathrm{Cl}-\mathrm{BTA}$. This may indicate that at $100^{\circ} \mathrm{C}$, there is not enough time for the formation of equilibrium adsorption films on the metal.

4. There are reasons to believe that upon prolonged chamber treatment of copper with vapors of substituted benzotriazoles ( 24 hours or more), equilibrium adsorption films of 
ChIn are formed thereon. In this case, the character of the effect of the ChIn properties on their protective after-effect changes. Under these conditions, the best metal protection is provided by the least volatile and most hydrophobic substituted benzotriazole, viz., ClBTA.

\section{Acknowledgements}

This study was carried out at A.N. Frumkin Institute of Physical chemistry and Electrochemistry of the Russian Academy of Sciences with support of the Russian Science Foundation (Grant No. 17-13-01413 "Fundamental principles of creation of ultra-thin passivating organic films on metals for protection against atmospheric corrosion").

\section{References}

1. J.Y. Malvaut, J. Lopitaux, D. Delahaye and M. Lenglet, Cathodic reduction and infrared reflectance spectroscopy of basic copper (II) salts on copper substrate, J. Appl. Electrochem., 1995, 25, 841.

2. I.L. Rozenfel'd and V.P. Persiantseva, Ingibitory atmosfernoi korrozii (Inhibitors of atmospheric corrosion), Moscow, Nauka, 1985 (in Russian).

3. C. Fiaud, Theory and Practice of Vapour Phase Inhibitors, in: Corrosion Inhibitors, 1994, London, The Institute of Materias, 1-12.

4. N.N. Andreev, Yu.I. Kuznetsov, Physicochemical aspects of the action of volatile metal corrosion inhibitors, Russ. Chem. Rev., 2005, 74, no. 8, 685-695.

5. D.M. Bastidas, E. Cano and E.M. Mora, Volatile corrosion inhibitors: a review, AntiCorros. Meth. Mater., 2005, 52, no. 2, 71-77.

6. A. Subramanian, M. Natesan, V.S. Muralidharan, K. Balakrishnan and T. Vasudevan, An overview: vapor phase corrosion inhibitors, Corrosion, 2000, 56, no. 2, 144-155.

7. N.N. Andreev and Yu.I. Kuznetsov, Progress in the fundamentals of volatile inhibitors of atmospheric corrosion of metals, in: Reviews on Corrosion Inhibitor Science and Technology, 2004, Houston, NACE International, II-1-II-18.

8. A.Yu. Luchkin, O.A. Goncharova, N.N. Andreev and Yu.I. Kuznetsov, A new method for metal protection for atmospheric corrosion, Praktika protivokorrozionnoi zashchity, 2017, no. 4, 7-12 (in Russian).

9. A.Yu. Luchkin, O.A. Goncharova, N.N. Andreev, Yu.I. Kuznetsov and N.P. Andreeva, Copper protection by treatment with vapors of low volatile inhibitors at elevated temperature, Korroz.: mater., zashch., 2017, no. 11, 25-31 (in Russian).

10. A.Yu. Luchkin, O.A. Goncharova, N.N. Andreev and Yu.I. Kuznetsov, Steel protection by treatment with vapors of octadecylamine, benzotriazole, and their mixture at elevated temperature, Korroz.: mater., zashch., 2017, no. 12, 20-27 (in Russian).

11. O.A. Goncharova, Yu.I. Kuznetsov, N.N. Andreev, A.Yu. Luchkin, N.P. Andreeva and D.S. Kuznetsov, A new corrosion inhibitor for zinc chamber treatment, Int. J. Corros. Scale Inhib., 2018, 7, no. 3, 340-351. doi: 10.17675/2305-6894-2018-7-3-5 
12. O.A. Goncharova, A.Yu. Luchkin, Yu.I. Kuznetsov, N.N. Andreev, N.P. Andreeva and S.S. Vesely, Octadecylamine, 1,2,3-benzotriazole and a mixture thereof as chamber inhibitors of steel corrosion, Int. J. Corros. Scale Inhib., 2018, 7, no. 2, 203-212. doi: 10.17675/2305-6894-2018-7-2-7

13. O.A. Goncharova, N.N. Andreev, A.Yu. Luchkin, Yu.I. Kuznetsov, N.P. Andreeva and S.S. Vesely, Protection of copper by treatment with hot vapors of octadecylamine, 1,2,3-benzotriazole, and their mixtures, Mater. Corros., 2018, doi: $10.1002 /$ maco.201810366 (in press).

14. O.A. Goncharova, A.Yu. Luchkin, Yu.I. Kuznetsov and N.N. Andreev, Vapor phase protection of zinc from atmospheric corrosion by low volatile corrosion organic inhibitors, Korroz.: mater., zashch., 2018, no. 8, 8-13. doi: 10.31044/1813-7016-2018$\underline{0-8-8-13}$

15. F. El Taib Heakal and S. Haruyama, Impedance studies of the inhibitive effect of benzotriazole on the corrosion of copper in sodium chloride medium, Corros. Sci., 1980, 20, 887-898.

16. R. Youda, H. Nishihara and K. Aramaki, SERS study on inhibition mechanisms of benzotriazole and its derivatives for copper corrosion in sulphate solutions Corros. Sci., 1988, 28, 87-96.

17. A.D. Modestov, G.-D. Zhou, Y.P. Wu, T. Notoya and D.P. Schweinsberg, A study of the electrochemical formation of $\mathrm{Cu}$ (I)-BTA films on copper electrodes and the mechanism of copper corrosion inhibition in aqueous chloride/benzotriazole solutions, Corros. Sci., 1994, 36, 1931-1946.

18. D. Tromans and G. Li, Electrochemical Growth of passivating CuBTA films on copper in aqueous chloride/benzotriazole solutions, Electrochemю Solid-State Lett., 2002, 5, B5-B8.

19. Z.D. Schultz, M.E. Biggin, J.O. White and A.A. Gewirth, Infrared-Visible Sum Frequency Generation Investigation of $\mathrm{Cu}$ Corrosion Inhibition with Benzotriazole, Anal. Chem., 2004, 76, 604-609.

20. J.E. Walsh, H.S. Dhariwal, A. Gutierrez-Sosa, P. Finetti, C.A. Muryn, N.B. Brookes, R.J. Oldman and G. Thornton, Probing molecular orientation in corrosion inhibition via a NEXAFS study of benzotriazole and related molecules on Cu (100), Surf. Sci., 1998, 415, 423-432.

21. H.Y.H. Chan and M.J. Weaver, A vibrational structural analysis of benzotriazole adsorption and phase film formation on copper using surface-enhanced Raman spectroscopy, Langmuir., 1999, 15, 3348-3355.

22. R. Youda, H. Nishihara and K. Aramaki, SERS and impedance study of the equilibrium between complex formation and adsorption of benzotriazole and 4hydroxybenzotriazole on a copper electrode in sulphate solutions, Electrochim. Acta, 1990, 35, 1011-1017. 
23. T. Kosec, D.K. Merl and I. Milošev, Impedance and XPS study of benzotriazole films formed on copper, copper-zinc alloys and zinc in chloride solution,Corros. Sci., 2008, 50, 1987-1997.

24. S.M. Milic' and M.M. Antonijevic', Some aspects of copper corrosion in presence of benzotriazole and chloride ions, Corros. Sci., 2009, 51, 28-34.

25. K.F. Khaled, Experimental and atomistic simulation studies of corrosion inhibition of copper by a new benzotriazole derivative in acid medium, Electrochim. Acta, 2009, 54, 4345-4352.

26. D. Gopi, K.M. Govindaraju, V. Collins Arun Prakash, D.M. Angeline Sakila and L. Kavitha, A study on new benzotriazole derivatives as inhibitors on copper corrosion in ground water, Corros. Sci., 2009, 51, 2259-2265.

27. M. Finšgar, A. Lesar, A. Kokalj and I. Milošev, A comparative electrochemical and quantum chemical calculation study of BTAH and BTAOH as copper corrosion inhibitors in near neutral chloride solution, Electrochim. Acta, 2008, 53, 8278-8297.

28. H.O. Curkovic, E. Stupnisek-Lisac and H. Takenouti, The influence of $\mathrm{pH}$ value on the efficiency of imidazole based corrosion inhibitors of copper, Corros. Sci., 2010, 52, 398-405.

29. M.M. Antonijevic', S.M. Milic' and M.B. Petrovic', Films formed on copper surface in chloride media in the presence of azoles, Corros. Sci., 2009, 51, 1228-1237.

30. G. Quartarone, M. Battilana, L. Bonaldo and T. Tortato, Investigation of the inhibition effect of indole-3-carboxylic acid on the copper corrosion in $0.5 \mathrm{M} \mathrm{H}_{2} \mathrm{SO}_{4}$, Corros. Sci., 2008, 50, 3467-3474.

31. F.M. Al Kharafi, A.M. Abdullah and B.G. Ateya, A quartz microbalance study of the kinetics of interaction of benzotriazole with copper, J. Appl. Electrochem., 2007, 37, $1177-1182$.

32. F.M. Bayoum, A.M. Abdullah and B. Attia, Kinetics of corrosion inhibition of benzotriazole to copper in 3.5\% NaCl, Mater. Corros., 2008, 59, 691-696.

33. A.D. Modestov, G.-D. Zhou, Y.-P. Wu, T. Notoya and D.P. Schweinsberg, A study of the electrochemical formation of $\mathrm{Cu}(\mathrm{I})$-BTA films on copper corrosion inhibition in aqueous chloride/benzotriazole solutions, Corros. Sci., 1994, 36, 1931-1946.

34. S. Mamas, T. Kiyak, M. Kabasakaloğlu and A. Koç, The effect of benzotriazole on brass corrosion, Mater. Chem. Phys., 2005, 93, 41-47. doi: 10.1016/j.matchemphys. 2005.02.012

35. F. El-T. Heakal and S. Haruyama, Impedance studies of the inhibitive effect of benzotriazole on the corrosion of copper in sodium chloride medium, Corros. Sci., 1980, 20, 887-898.

36. F.M. Al Kharafi, A.M. Abdullah, I.M. Ghayad and B.G. Ateya, Effect of sulfide pollution on the stability of the protective film of benzotriazole on copper, Appl. Surf. Sci., 2007, 253, 8986-8991. 
37. Z. Mountassir and A. Srhiri, Electrochemical behaviour of $\mathrm{Cu}-40 \mathrm{Zn}$ in $3 \% \mathrm{NaCl}$ solution polluted by sulphides: Effect of aminotriazole, Corros. Sci., 2007, 49, 13501361.

38. H. Ma, S. Chen, B. Yin, S. Zhao and X. Liu, Impedance spectroscopic study of corrosion inhibition of copper by surfactants in the acidic solutions, Corros. Sci., 2003, 45, 867-882.

39. F. Mansfeld, M.W. Kendig and S. Tsai, Evaluation of Corrosion Behavior of Coated Metals with AC Impedance Measurements, Corrosion, 1982, 38, no. 9, 478-485.

40. F. Altaf, R. Qureshi and S. Ahmed, Surface protection of copper by azoles in borate buffers - voltammetric and impedance analysis, J. Electroan. Chem., 2011, 659, 134142.

41. Z. Chen, L. Huang, G. Zhang, Y. Qiu and X. Guo, Benzotriazole as a volatile corrosion inhibitor during the early stage of copper corrosion under adsorbed thin electrolyte layers, Corros. Sci., 2012, 65, 214-222.

42. V.I. Kichigin, I.N. Sherstobitova and A.B. Shein, Impedance of electrochemical and corrosion systems, Perm, Perm state university, 2009, 238 pp. (in Russian).

43. T. Kosec, D. Kek Merl and I. Milošev, Impedance and XPS study of benzotriazole films formed on copper, copper-zinc alloys and zinc in chloride solution, Corros. Sci., 2008, 50, 1987-1997.

44. N.N. Andreev and Yu.I. Kuznetsov, Estimation of saturated vapor pressure of aromatic compounds, Zh. Phys. Chem., 1993, 67, no. 9, 1912-1914 (in Russian).

45. N.N. Andreev and Yu.I. Kuznetsov, Estimation of saturated vapor pressure of aromatic compounds, Zh. Phys. Chem., 1993, 67, no. 10, 1979-1982 (in Russian).

46. N.N. Andreev, Yu.I. Kuznetsov and T.Yu. Storozhenko, Prediction of vapour pressure and boiling points of aliphatic compounds, Mendeleev Commun., 1994, 5, 173-174.

47. N.N. Andreev and Yu.I. Kuznetsov, Strategy in volatile corrosion inhibitors design, 8th European Symposium on Corrosion Inhibitors, Ferrara, 1995, 651-662.

48. N.N. Andreev and Yu.I. Kuznetsov, Prediction of vapor pressures of volatile corrosion inhibitors, Zashch. Met., 1996, 32, no. 2, 163-169 (in Russian).

49. N.N. Andreev, On the quantitative estimation of vapor pressures of volatile corrosion inhibitors, Zashch. Met., 1998, 34, no. 2, 123-133 (in Russian). 